Herrera, Carlos; "Los partidos socialistas de Ricardo Falcón". Cuadernos del Ciesal, Rosario, UNR, $\quad \mathrm{N}^{\mathrm{o}} \quad 20, \quad 2021, \quad$ pp. $\quad 1-24, \quad$ ISSNe $1853-8827$. https://cuadernosdelciesal.unr.edu.ar/index.php/inicio

\title{
Los partidos socialistas de Ricardo Falcón
}

Carlos Herrera ${ }^{(*)}$

\section{Resumen}

El trabajo analiza desde una perspectiva historiográfica la obra de Ricardo M. Falcón sobre el Partido Socialista. El artículo se centra en las principales hipótesis trabajadas por el autor, así como en su perspectiva teórica y política, la cual se puede ver reflejada a lo largo de las casi cuatro décadas de trayectoria académica, sintetizadas en el presente escrito. Paralelamente, se realiza una retrospectiva de sus aportes a la historia social, centrada en los sectores populares, que fue el otro gran tema presente en los escritos de Ricardo Falcón.

Palabras clave: Partido socialista; Sectores populares; Sindicalismo.

\section{The socialist partys by Ricardo Falcón}

\begin{abstract}
This work analice from a historiographic perspective, the work of Ricardo Falcón about the Socialist Party. This article focusing in the principals hypothesis worked by Falcon, as in their theoretical and political perspective, wich is could be observed along about almost four decades of academic trajectory, wich are synthesized in this paper. Parallel, is held a restrospective about the contributions to the social history, centered in the popular sectors, that was the other great contribution realized by Ricardo Falcón.
\end{abstract}

Key Words: Socialist party; Popular sectors; Sindicalism.

\footnotetext{
(*) Abogado por la Universidad de Buenos Aires, Doctor en Lettres et sciences humaines por la Université Paris Ouest Nanterre La Défense, profesor catedrático de la Université de Cergy-Pontoise, miembro honorario del Institut Universitaire de France y profesor invitado en universidades de Argentina, Colombia, España y Rusia. Mail: carlos.herrera@u-cergy.fr ORCID: https://orcid.org/ $\underline{0000-0002-7002-6121}$
} 


\section{Los partidos socialistas de Ricardo Falcón ${ }^{1}$}

\section{Introducción}

La obra de Ricardo Falcón se caracterizó por una gran estabilidad de temas y períodos trabajados, que se centraron en el surgimiento y los primeros desarrollos del movimiento obrero argentino, con particular énfasis entre la segunda mitad del siglo XIX y la primera experiencia radical de gobierno, aunque ambos límites fueron expandidos en varias ocasiones.

Dentro de esa permanencia, el Partido Socialista se constituyó, naturalmente, en uno de sus objetos recurrentes, y nos ofrece, de alguna manera, un ángulo para explorar el conjunto de su producción. De hecho, en el último de sus trabajos, aparecido de manera póstuma, Falcón destacaba que el movimiento obrero y el movimiento socialista surgieron al mismo tiempo en Argentina, naciendo (en los inicios de los años 1880) e irrumpiendo juntos (en 1890) en la escena política (Falcón, 2011: 13).

Y, en efecto, su primer trabajo académico, realizado en el exilio europeo a fines de 1979, se ocupaba ya de la cuestión, a partir de una exploración de los tres primeros congresos partidarios. No por casualidad, tampoco, en sus últimos textos anunciaba un libro sobre Los orígenes del socialismo en la Argentina 1830-1900, que quedó trunco. En ese arco temporal que cubrió tres décadas, Falcón desarrolló un conjunto de estudios, que incluyeron el análisis de la propagación del socialismo en la ciudad de Rosario. Por cierto, fue un historiador comprometido con su tiempo -que había llegado a "la historia por la política", como él mismo lo repetía, ${ }^{2}$ y que pensaba hasta el final que ella servía "para encontrar explicaciones a la acción política hoy" (Gotta-Múgica, 2008: 78)-, el quehacer académico no agotaba todo lo referido al socialismo argentino: a mediados de los años 1990 Falcón se incorporó al Partido Socialista Democrático en su ciudad natal y poco tiempo después celebró la reunificación partidaria que se concretaría en 2002. Tres años más tarde, desde las páginas del emblemático La Capital, hablaba de un renacimiento socialista, donde vulgarizaba algunas de las conclusiones de sus investigaciones previas (Falcón, 2005b). Al fin y al cabo, se referiría a sí mismo como un "intelectual orgánico del socialismo" (Glück, 2011: 32).

A su vez, Ricardo Falcón ocupó, como historiador del socialismo, un lugar intermedio entre dos generaciones, la que había unido práctica historiográfica y militancia política, y la nueva generación de historiadores profesionales -la "primera", a su juicio, que "se constituye como corporación a partir del '83” (Gotta-Múgica, 2008: 77)-. En el medio, su formación, y luego su

\footnotetext{
${ }^{1}$ El autor agradece a María Pía Martín y Paulo Menotti por el envío de algunos materiales, y a Patricia Ledesma Fernández y Hernán Camarero por sus lecturas.

${ }^{2}$ Falcón había sido un activo militante político del grupo trotskista Política Obrera (Poy, 2013). Al final de su vida, Falcón recordará la importancia que tuvo para su formación un autor de la otra corriente trotskista con la que había tenido contacto previamente, Milcíades Peña (Gotta-Múgica, 2008: 85).
} 


\section{Carlos Herrera}

obra, sufrirán el impacto de la dictadura militar y del exilio, ${ }^{3}$ que marcará también la profesionalización de los saberes en la transición democrática. Al mismo tiempo, Falcón ocupó también un lugar intermedio en la historiografía socialista, entre los antiguos estudios ensayísticos y la nueva historia universitaria del Partido Socialista que se instala a principios de los años 2000. Aquí podríamos decir que habiendo sido crítico de la primera fue sin duda un precursor de la segunda, que tuvo, de algún modo, ocasión de reivindicarlo. ${ }^{4}$

Empero, en el marco de esa estabilidad temática que apuntábamos, ¿cómo afectó a su visión del socialismo argentino, sus evoluciones historiográficas, en particular dentro del campo de la historia social? Ciertamente, acaso con excesiva coquetería, Falcón negaba tener una "formación epistemológica", aseverando ser un historiador bastante tradicional, al menos en relación con el dato empírico (Gotta-Múgica, 2008: 78). ${ }^{5}$ Como sabemos, su primer trabajo se enmarcaba todavía en una visión marxista y hasta el final de sus días se definirá como "hegeliano-marxista". De regreso al país, Falcón se integró en otras empresas historiográficas que, inspirándose de la tradición inglesa abierta por autores como Edward P. Thompson, terminaría diseñando un relato articulado en torno al concepto de "sectores populares". ${ }^{6}$ A fines de los años 1980, el propio Falcón celebrará una puesta entre paréntesis del concepto de "clase obrera", al menos en lo referente a los primeros tiempos de la historia de los trabajadores en Argentina, que estimaba "saludable" (Falcón, 1988: 165). En verdad, como lo escribía entonces, dicho concepto sólo le parecía parcialmente pertinente, en particular para tratar los primeros intentos organizativos, antes de la conformación del movimiento obrero propiamente dicho.

Aunque sus principales impulsores en el ámbito local habían parecido querer limitar rápidamente su portée para el período $1850-1880,{ }^{7}$ Falcón lo conservará hasta el final de su producción, afirmando que la capa de artesanos y asalariados de la segunda mitad del siglo XIX "formaban parte de lo que hoy solemos denominar sectores populares", que se expresaban a través de conjunto de actividades culturales y políticas, y podían ser considerados, al menos parcialmente, "como antecesores de una clase obrera que estaba adquiriendo identidad propia" (Falcón, 2011: 23). Más relevante aún, Falcón dejaba ver, en el marco de la alta movilidad

\footnotetext{
${ }^{3}$ Falcón hará referencia a la importancia del exilio, que inició en Brasil, en 1977, y se prolongará en París entre febrero de 1978 y mayo de 1984, para su formación intelectual (Gotta-Múgica, 2008: 74).

${ }^{4} \mathrm{Al}$ menos, él lo sentía así tras la publicación de Camarero-Herrera (2005).

${ }^{5}$ Hacia el nuevo siglo XXI, estimaba que los problemas complejos de la cuestión social, pasada y presente, podían ser abordados por lo que llamaba, sin mayores precisiones, el "método estructural", completado por el estudio de lo simbólico como enfoque complementario (Falcón, 2000b, p. 181).

${ }^{6}$ Ver el texto programático de Romero (1987). Para un análisis crítico de esa lectura de Thompson, ver Nieto (2013: 380-389).

${ }^{7}$ Ver Sábato-Romero 1992. En rigor, el texto programático de Romero ya aludido no se ocupaba tanto del Buenos Aires del siglo XIX (su referencia era, de hecho, el período 1880-1940, centrándose en Chile para el período anterior), sino que buscaba establecer, sobre todo, que la identidad popular no era un núcleo cerrado, sino un polo cambiante, e incluso un campo de conflicto, donde compiten varios discursos, que buscan moldear esa identidad, entre ellos, el socialista, que lo hacía en términos de identidad trabajadora (Romero, 1987: 222, 215). El concepto será proyectado, ya en términos de sujeto alternativo a la clase obrera, que afloraba en el artículo citado, sobre todo en el período de entreguerras.
} 
social de esos años 1870 y 1880 , un proceso por "escisión" al interior de esos sectores populares urbanos, del que surgirá el proletariado (Falcón, 2011: 28).

Sin embargo, y desde un primer momento, llamará a una combinación de enfoques sociales, culturales y políticos. En efecto, podemos adelantar ya una de las tesis de este trabajo, a saber, que Falcón, a diferencias de otros exponentes del giro neothompsoniano, no quedará encerrado en los términos del debate así planteado, o en todo caso, buscará, en los hechos, superarlo, recurriendo al concepto de identidad política.

Si el análisis de sus diferentes ensayos sobre el socialismo argentino revela sus evoluciones historiográficas -posiblemente también políticas-, su lectura de conjunto deja al descubierto, al mismo tiempo, un relato rico sobre el devenir del socialismo argentino en las primeras décadas.

\section{El PS frente al movimiento obrero}

Su primer artículo de 1979 no sólo reflejaba las marcas de su adscripción política de entonces, ligada al trotskismo, sino también la influencia de algunas lecturas previas desde el marxismo, como el libro de José Ratzer, Los marxistas argentinos del 90, aparecido diez años antes, en particular para relevar la importancia del dirigente socialista de origen alemán Germán Avé Lallemant, cuyo conocido análisis del radicalismo aprobaba (Falcón, 1979: 65) -algunos años más tarde juzgará esta valorización más críticamente, como un intento de encontrar un precedente al leninismo (Falcón, 2008: 2)-. En este ensayo, que mostraba ya algunas de las cualidades de su trabajo de historiador, Falcón reconstruía los debates en los primeros congresos socialistas, apoyándose en los artículos publicados en La Vanguardia, La Montaña y en publicaciones anarquistas como $L^{\prime}$ Avvenire. ${ }^{8}$

Tal vez el principal aporte de este estudio residía en recordar que el liderazgo de Justo sólo se concretaría tras "una aguda lucha política entre los núcleos opositores", que se inscribía a su vez en una historia del socialismo "poblada de tendencias y escisiones antirreformistas de distinto signo" (Falcón, 1979: 58). En ese marco, Falcón ponía de relieve lo que constituía la especificidad de las controversias que precedieron al afianzamiento del justismo, cuando estaba abierta una disputa interna por el programa y por el tipo de partido que se buscaba estructurar. En las tempranas posiciones de Justo, expresadas sobre todo en el llamado Congreso Constituyente de 1896, Falcón veía ya claramente establecido el predominio de la lucha política y de sus medios específicos, por sobre toda otra forma de resistencia, en particular en el terreno del movimiento obrero, y de toda otra forma organizativa y de acción. Al mismo tiempo, la

\footnotetext{
${ }^{8}$ En el contexto argentino de la época, la tesis de Ricardo Falcón se valorizaba particularmente por su trabajo de archivo en centros europeos, que le permitía despegar un amplio y sólido material empírico para sostener sus hipótesis.
} 


\section{Carlos Herrera}

posibilidad de otra estrategia para el proletariado tampoco parecía darse por sentada, y en todo caso, la lucha política era el único camino para prepararse a otros eventuales medios de acción. Los aciertos de este promisorio trabajo distaban de ser escasos: la existencia de un partido previo a 1896, el peso de la fundación de La Vanguardia, la significación de la personalidad de Justo, la ausencia de bloques consolidados en las divergencias, son los principales. Ya aparecía también aquí su interés por José Ingenieros, que Falcón tendrá la ocasión de tratar con mayor relieve en una tesina universitaria preparada en esos años parisinos, ${ }^{9}$ del que resaltaba su manera específica de procesar las divergencias entre socialistas y anarquistas, y que lo ubicaba en una especie de tercera vía, entre el parlamentarismo de Justo y el reformismo apoliticista de los anarquistas (Falcón, 1979: 69-70, 73).

Por cierto, la idea de luchas políticas "que se generaban como un reflejo de los acontecimientos de la lucha de clases" (Falcón, 1979: 58) era la principal tesis metahistórica de Falcón. Y aunque no dejara de apuntar otras causas en la conformación de esta línea, las posiciones de Justo eran evaluadas a partir de la "incomprensión de carácter semicolonial de la Argentina", un naciente capitalismo que se desenvolvía ya en su fase imperialista, y cuyo desconocimiento le impedía "fijar con claridad las tareas necesarias para que el proletariado se abriera políticamente camino a través de su partido (Falcón, 1979: 65).

Más aún, haciendo hincapié en los debates que se produjeron en las dos coyunturas partidarias de 1896 y de 1898, e incluso antes, en 1894, Falcón concluía que "desde el punto de vista programático el reformismo justista constituía un retroceso en relación a las posiciones de los primeros socialistas argentinos anteriores a la constitución del partido", que relacionaba por entonces con el marxismo. Pero al mismo tiempo, el justismo aparecía como "una propuesta coherente", antes de agregar, en clave normativa, que la constitución de un partido obrero, aunque reformista, era una "alternativa por la que necesariamente un sector de la clase obrera tenía que pasar" (Falcón, 1979: 81-82).

En verdad, desde sus posiciones metodológicas y políticas de entonces, Falcón estimaba que la debilidad de sus planteos para una definición no reformista de la estrategia socialista venía de la omisión de la dictadura del proletariado (aunque dejaba abierta la posibilidad que fuera el producto del deficiente conocimiento de la teoría marxista que se tenía por entonces en el país). Por cierto, el economicismo de los llamados "colectivistas" era también puesto de manifiesto,

\footnotetext{
${ }^{9}$ Para Falcón, Ingenieros fue uno de aquellos pensadores en que se encarnó el intelectual de izquierda y el que mayor preocupación mostró por el problema de la relación entre el intelectual y la política (Falcón, 1985: 177-178). Su gusto por la periodización lo llevará a distinguir tres etapas en el pensamiento de Ingenieros, la del socialista revolucionario (1894-1897), la del sociólogo socialista (que se extiende hasta el comienzo de la Gran Guerra) y finalmente la del intelectual de izquierda independiente. Los giros del pensamiento de Ingenieros estaban ligados a la situación del capitalismo y de su posible evolución, donde alterna visiones negativas y positivas, retomando una tesis de Oscar Terán ( p. 187). La independencia será una afirmación constante, con una lucidez antidogmática para captar el elemento determinante de cada momento (y que asocia a su oportunismo), y la certeza sobre la misión central de los intelectuales en la política, relacionada con su visión de las minorías actuantes. Lo que lo distingue del intelectual del partido leninista.
} 
con un campo de acción que, a su vez, se veía restringido por la presencia de los anarquistas en el ámbito sindical.

Las líneas de análisis se mantenían en la tesis doctoral que defendería en París en 1985, y del cual publicará un avance en la Argentina de la "primavera democrática", recién llegado del exilio, aunque el tono militante había desaparecido. Podía leerse allí que el estudio del Partido Socialista sólo podía concebirse dentro de la historia del movimiento obrero, que a su vez era puesta "en directa relación con el proceso de conformación de la clase obrera y del conjunto de transformaciones sociales de la época", es decir, como un fenómeno de historia social (Falcón, 1984: 9-10). En efecto, recusaba explícitamente una historia política que la concebía como "un fenómeno relativamente autónomo del proceso social", aunque no descartaba la consideración de los elementos políticos, ideológicos, e incluso individuales (Falcón, 1984: 9-10).

Falcón destacaba el peso de las transformaciones de la formación social argentina, ya sea en el campo de la producción o por efecto de la inmigración. En ese desarrollo, apuntaba que a partir de 1890 las principales iniciativas en el terreno sindical venían de los socialistas, y esa dinámica entre los trabajadores, en particular los intentos de constituir una federación, estaban en la base de la formación del futuro partido (Falcón, 1984: 84). Poco después, con la propia evolución del anarquismo, le surgiría un adversario de peso. Para Falcón, tras el retorno de los colectivistas al Partido, en 1900, el socialismo ostentaba sus rasgos definitivos, que lo mostraban como "un partido reformista que ejercería su acción a través de la acción parlamentaria fundamentalmente, presentando un programa de reivindicaciones sociales y económicas de los trabajadores de reformas democráticas y republicanas del sistema político", que tenían su modelo en el partido australiano (Falcón, 1984: 103).

\section{El PS y los sectores populares}

De alguna manera, su tesis doctoral involucraba ya un tránsito hacia nuevos rumbos. En las rápidas consideraciones metodológicas que acompañan su publicación resumida en castellano, encontramos ya el impacto de las teorías de Thompson, que Falcón retraduce en su propio estudio como una orientación que prioriza, escribe, el mundo del trabajo más que el examen de las condiciones de trabajo. Esto redundaba en un análisis de las organizaciones obreras que dejaba de lado los aspectos políticos e ideológicos para encararlas como un "fenómeno social y cultural", en lo que primaba su incidencia en la cultura del trabajo. Aclaraba, con todo, que lo que sincrónicamente podía ser visto como el mundo de los trabajadores, diacrónicamente representaba el proceso de formación de la clase obrera (Falcón, 1986: 10). 


\section{Carlos Herrera}

El Partido Socialista aparecía como la vía de integración de un sector del movimiento obrero que avizoraban las élites gobernantes (o más exactamente una de sus líneas), a través de la promoción de la legislación social, por sus diferencias estratégicas con el anarquismo e incluso el radicalismo. Pero la cuestión dividía al propio partido desde adentro, en particular los sectores sindicales, que rechazaban sin atenuantes el proyecto de Joaquín V. González, y algunos juristas, aunque la propia dirección, como lo anotaba Falcón, no quería comprometerse con el proyecto gubernamental, pero dejando abierta tácticamente la cuestión de la intervención del Estado en pos del mejoramiento de las clases obreras (Falcón, 1986: 75, 79).

El planteamiento marxista se difuminaba poco después en algunas de las investigaciones que marcan, acaso, el pico de su producción académica. En el primero de esos trabajos, tras insistir en sus tesis sobre la doble estrategia del socialismo, es decir reformas políticas profundas y mejoramiento económico de la clase obrera, unidas por el nexo político de la acción parlamentaria, y la contestación que la misma sufría en el seno del Partido desde los años 1890 a la salida de los sindicalistas revolucionarios, retomaba algunas de las ideas del artículo publicado en el exilio (Falcón, 1987: 195). Pero cuando reconstruye los perfiles de sus principales dirigentes los ubica prevalentemente en el campo intelectual, con rasgos comunes, entre los que descollaba el proceso de "argentinización" del socialismo, ligado pues a aquella estrategia, que había sido precedida por el reconocimiento de un nuevo espacio político en lo que Falcón llamaba los “crecientes movimientos sociales urbanos” (Falcón, 1987: 198). Por lo pronto, el Partido se veía beneficiado por el ingreso en sus filas de hombres provenientes de los sectores medios, en particular universitarios, lo que no dejaba de acarrear las referidas contradicciones internas, como se expresaba en la discusión en torno al proyecto González de Código de Trabajo, y luego en la nueva escisión de 1904. Cuando recién un lustro más tarde el socialismo recuperaba su caudal de afiliados, estos provenían, según la hipótesis de Falcón, “a distintas capas de los sectores medios" (Falcón, 1987: 203).

Pero era a los "sectores populares" o "sectores populares urbanos" que se dirigían también los proyectos de integración en materia de trabajo (Falcón, 1987: 213) o aun las propuestas anarquistas en materia inmigratoria, a la que se sumarán luego los radicales (Falcón, 1987: 214, 218-220). Si esta categoría se extravía algo en el despliegue del eje de su reflexión, ${ }^{10}$ el problema de la extranjería y los otros particularismos étnicos, o mejor dicho, pierde algo de rigor metodológico, indicaba una nueva orientación en su reflexión sobre el socialismo, y más generalmente de las izquierdas, que permeaba ya claramente en el artículo. Ese "vasto sector de artesanos, trabajadores independientes, comerciantes ambulantes", al que se sumaban los “intelectuales" (Falcón, 1987: 206) empieza a rendir sus frutos, dándole a lo político una

\footnotetext{
${ }^{10}$ No tiene parangón, por ejemplo, con la distinción que hacía, en referencia al anarquismo, entre "discurso de clase obrera" y “discurso de los oprimidos" (Falcón, 1987: 206).
} 
autonomía con respecto a "una supuesta identidad 'natural' ideología-grado de estructuración capitalista", que de hecho explicaba el éxito anarquista (Falcón, 1987: 211). ${ }^{11}$

Inmediatamente después, en dos ensayos sucesivos, Falcón daba entidad metodológica a la categoría que marcaría una perspectiva diferente a la que calificaba de "tradicional" historia del movimiento obrero, término este que aludía a las historias hechas por militantes, en favor de una nueva historia social de los trabajadores, cuyos referentes eran historiadores ingleses (E. P. Thompson, Eric Hobsbawm) y franceses (Rolande Trempé, Michelle Perrot). Desde luego, Falcón asociaba el cambio de paradigma a la profesionalización de la historia de los trabajadores, cuyos antecedentes databa de los años 1960 (Falcón, 1988: 163; Falcón, 1989: 155). No dejaba de subrayar, tal vez para preparar la originalidad de su propio aporte en el campo de una sociología histórica, que en Argentina, los nuevos estudios se concentraban en las condiciones de vida y hábitos materiales de los trabajadores, o que llamaba "el mundo del consumo" (Falcón, 1988: 165, 172; Falcón, 1989: 158-159). ${ }^{12}$ En todo caso, el concepto de "sectores populares" suponía implícitamente que "no se ha constituido aún una clase obrera" (Falcón, 1988: 165). Convenía entonces hablar de un "proceso de construcción, de constitución, permanente de la clase obrera $-\mathrm{y}$ no de su simple determinación por los grados de industrialización- tal como lo hace E. P. Thompson" (Falcón, 1989: 165).

Se debía entonces concebir la formación de la clase obrera como un proceso abierto y de transformaciones. En el caso argentino, situaba ese estadio primitivo -el uso de este término delataba malgré lui la persistencia de sus antiguas visiones- entre 1860 o 1870 hasta por lo menos el período 1910-1914, que extiende enseguida a título de hipótesis hasta los años 1930 (Falcón, 1988: 166). En realidad, las periodizaciones no eran lineales, y podían tener puntos de quiebre. En ese sentido, para Falcón, no se podía descartar el concepto de "clase" en determinadas coyunturas en que los trabajadores, aun siendo núcleo heterogéneo, actuaban como un sector diferenciado políticamente, dispuesto a enfrentar a las clases dominantes y al Estado. Un discurso ideológico, aparecía vehiculado en las tres corrientes de la izquierda argentina, que podía coincidir con las representaciones que los trabajadores hacían de su propia

\footnotetext{
11 Los socialistas, según Falcón, centraban su prédica en los inmigrantes y sus descendientes, llamando a abandonar sus nacionalidades e identidades en aras de la organización política y social de la clase obrera, pero en un contexto en que los extranjeros estaban marginados de la política (Falcón, 1987: 211, 214). A su vez, esto permitía a Falcón cuestionar la tesis del "tercer revisionismo", aquel de los años 1960 et 1970, que situaba al socialismo de espaldas a lo nacional (Falcón, 1987: 217). Había incluso puntos de contacto con la empresa que desarrollaban las élites gobernantes, aunque el socialismo la desplegaba en el terreno político y desde abajo, como escribe más tarde, como acción que coronaba la intervención de los trabajadores en la lucha de clases (Falcón, 2008: 25 y Falcón, 2011: 17).

${ }^{12}$ En ese sentido, apuntaba la insuficiencia de centrar la cuestión en torno del concepto de "cultura", como se venía realizando según él desde la obra de Leandro Gutiérrez y el programa que inspiraba junto a Luis Alberto Romero, el PEHESA (Falcón, 1988: 167 y Falcón, 1989: 158-159). Aunque en el libro que reunirá posteriormente sus principales trabajos sobre el tema, Luis Alberto Romero señala la gran afinidad de inquietudes con el grupo de Rosario en esos años 1980 (Romero, 1995: 21), Falcón dejaba constancia del divorcio entre producción académica y militancia política y social, tan diferente de la historiografía inglesa, que por esos años creía ver y que ligaba a la centralidad del peronismo en la dirección del movimiento obrero, pero que podía ser también la expresión de una nueva relación entre los intelectuales y la política (Falcón, 1988 y 1989: 166-168). Más tarde el historiador rosarino se considerará el introductor en Argentina de los conceptos de cultura y mundo del trabajo (Gotta-Múgica, 2008: 76).
} 


\section{Carlos Herrera}

existencia. De manera general, este traducía el peso de los artesanos, más que de los trabajadores de fábrica, en la construcción del movimiento obrero, que no se limitaba al caso argentino, sino que tenía vetas universales.

Por ello llamaba a no disociar, desde un punto de vista más abstracto, lo social de lo político (Falcón, 1988: 168). Se trataba de superar el tipo de inserción de los trabajadores en los procesos de producción, tomando en cuenta los comportamientos políticos de los mismos en ciertas coyunturas y en algunas prácticas del conflicto social. Pero finalmente, era en el "terreno de la lucha social donde se expresa el proceso de constitución de las clases" (Falcón, 1988: 169). Sin embargo, en la Argentina de la época había quedado sin resolver el problema de la integración política de los trabajadores. Esto se explicaba, según Falcón, porque los trabajadores se habían constituido antes en obreros que en ciudadanos (Falcón, 1988: 170). Las dificultades del Partido Socialista, la única fuerza de izquierda que planteaba la integración política de los trabajadores se enraizan justamente allí (Falcón, 1988: 170-171).

En este, su momento más promisorio como historiador, Falcón promovía un enfoque global "una historia de los trabajadores con pretensión de globalidad" (Falcón, 1989: 150)-, que aunase mundo del consumo/mundo del trabajo, prácticas cotidianas/prácticas de las élites de los trabajadores, o aun cultura/ideología, buscando siempre sus íntimas conexiones y descartando toda unilateralidad. Retomando su distinción entre diacronía/sincronía, llamaba a dar cuenta de los aspectos institucionales y no institucionales de esa historia (Falcón, 1989: 165).

Una década después, esta ambiciosa propuesta no había logrado plasmarse en su obra. Su texto de síntesis sobre "Los trabajadores y el mundo de trabajo" daba cuenta de ello: la amplia erudición, sus reconstrucciones rigurosas sobre las condiciones de los trabajadores en los tres principales centros urbanos del país terminaban desembocando sin embargo en un análisis puramente empírico, dentro de una historia social muy general. No obstante, esas amplias hojeadas se volcarían más tarde en sus nuevos análisis sobre el socialismo argentino. De manera contemporánea, un conjunto de tesis analíticas venía a articular las diferencias entre cuestión social/cuestión obrera. Si la primera era presentada como "las contradicciones y problemas que surgen en el proceso de construcción capitalista", ella había antecedido en la Argentina el establecimiento de una sociedad capitalista. La cuestión obrera había aparecido dentro de ella, como su principal manifestación urbana, y el movimiento obrero, como expresión corporativa y política de los trabajadores, será una de sus manifestaciones, junto a otros variados actores (poderes públicos, empresas, intelectuales, etc.), que desplegaban distintas estrategias (revolucionarias, reformistas, conformistas, reaccionarias) (Falcón, 2000b: 189-190). ${ }^{13}$

\footnotetext{
${ }^{13}$ La tesis tenía una prolongación en el presente, cuando Falcón afirmaba que la cuestión obrera había perdido peso en materia de cuestión social actual (Falcón, 2000b: 190).
} 
Mientras tanto, hacía suya la tesis de los socialistas, que veían en la persistencia de las identidades nacionales de los inmigrantes un factor de retraso en la fusión de los trabajadores en un proletariado. Anotaba lógicamente el progreso que significaron para ese fin la creación de asociaciones mutualistas por oficio, ya que el nacimiento de organizaciones sobre bases clasistas se convertiría en un poderoso instrumento de integración, deteniéndose en la Sociedad Tipográfica Bonaerense como el ejemplo más perdurable (Falcón, 1999: 502) Sólo hacia 18771880, con las primeras huelgas, nacerían las sociedades de resistencia, una vez más en el seno de los trabajadores "gráficos". ${ }^{14} \mathrm{Al}$ mismo tiempo, con El Artesano, cuyo primer número salía de imprenta en marzo de 1863, Falcón databa el origen de una prensa que podía calificarse "genéricamente de socialista, republicana, reformista", si no socialista al menos socialrepublicana (Falcón, 1999: 504). El historiador rosarino reconstruía rápidamente el pensamiento de Victory y Suarez y de otros autores del período que daban inicio al contacto con el movimiento europeo de la AIT, en cuyos contactos, que fijaba en enero de 1872, se detenía. De allí surgía la incompatibilidad entre la estrategia propugnada por la Internacional con la tradición mutualista, legalista y reformista que se venía desarrollando en nuestro país (Falcón, 1999: 509-522).

En uno de los últimos trabajos que Falcón realiza en el marco de ese paradigma, ${ }^{15}$ la Nueva Historia Argentina, en la que dirige el volumen correspondiente al período 1916-1930, aparece ya una orientación que terminará devengando su interés en la reconstrucción del socialismo argentino. Este período veía un PS sitiado desde diversos frentes, o al menos convertido en un enemigo común del radicalismo, sobre todo en el plano electoral en el ámbito capitalino, y del sindicalismo, que disputaba con los socialistas la dirección del movimiento sindical (Falcón y Montserrat, 2000: 156).

No por nada, su trabajo se centraba en las dos crisis que atravesaría el Partido en ese período, la que se producía contemporáneamente con la Revolución Rusa, y la que se producía en torno del llamado Socialismo independiente. Ambas tenían en común el poner a prueba la identidad del Partido. Lo interesante aquí es que Falcón da a entender que ambas escisiones, tan distintas entre sí, no conllevaban diferencias de principio con el viejo partido. En el caso de los Internacionalistas esto quedaba de manifiesto en las escasas diferencias programáticas que exhibe la nueva organización, donde tampoco las tácticas divergían demasiado -Falcón recordaba que los izquierdistas proclamaban su fidelidad a la declaración de principios, e incluso se veían como los auténticos continuadores de las antiguas posiciones ahora abandonadas por el grupo parlamentario (Falcón, 2000a: 342)-. En el segundo caso, eran diferencias tácticas, que irían dibujando luego divergencias estratégicas, pero no cuestiones de

\footnotetext{
${ }^{14}$ En cambio, el acta de nacimiento del movimiento obrero propiamente dicho era de 1888 (Falcón, 2000b: 190).

${ }^{15}$ Aunque tal vez convenga estudiar esta obra como el relato-síntesis de la generación del '83. Sobre este abordaje, ver Acha (2008).
} 


\section{Carlos Herrera}

principio, sin que hallase tampoco aquí "grandes diferencias organizativas ni programáticas" entre ambas fuerzas, donde según Falcón, jugaban sobre todo la autonomía profesional de ciertos sectores partidarios que alcanzaron influencia en sectores medios y juveniles del Partido, un contacto con las élites argentinas, y no poco oportunismo (Falcón, 2000a: 348-349). A contraluz de este análisis, se recortaba una identidad socialista fuerte, sobre la que consagrará Falcón su última década de trabajo.

\section{El PS y su identidad política}

Siguiendo los propios términos dicotómicos que había buscado superar con su propuesta, quizás se podría conjeturar que, ante la imposibilidad de realizarlo en la propia historia social, terminó regresando a lo que concebía como el ámbito de lo político-ideológico. Pero lo hacía de una manera renovada, donde el concepto mismo de "identidad política" aparecía como una posible síntesis, o al menos una alternativa al unilateralismo cultural que buscaba evitar, y que se volcaba, como veremos enseguida, en la cuestión de la formación de la clase obrera.

La (pen)última estación de Falcón tenía como marco la historia de su propia ciudad, la "Barcelona argentina" como la había definido el dirigente socialista Enrique Dickmann, que había tenido un largo alumbramiento (Falcón, 1992). Allí se proyectaban las identidades políticas que quería estudiar, y que se definían tanto por su modernidad como por su relación con las clases sociales (Falcón, 2005a: 14). El estudio de caso era aún más relevante para el problema historiográfico que lo desvelaba ya que el Partido Socialista era relativamente débil en esas geografías, una perspectiva acaso exagerada por la ausencia de cuadros partidarios políticos y de intelectuales orgánicos (Falcón, 2005a: 166). ${ }^{16}$ A escala rosarina se repetía la centralidad de la lucha política, en particular por vía legislativa, que perseguía dos objetivos "la profundización republicana y democrática de la sociedad política y la construcción de la clase obrera", pero que eran concebidas como los pilares para la conquista del poder político (Falcón, 2005a: 169). ${ }^{17}$ Pero esta línea integraba en sus políticas a otros sectores sociales (a la clase

\footnotetext{
${ }^{16}$ Para Falcón la explicación de esta carencia de dirigentes se encuentra en la ausencia de vida universitaria en las primeras décadas del siglo XX. La debilidad general tenía que ver, aparte de la competencia anarquista, que se veía favorecida por una sociedad con mayor escisión social, y una variante "obrerista" del radicalismo que le agregaba nuevos terrenos de disputa que no existían a nivel nacional, sobre todo, al menos a partir de 1908 con la existencia de una fuerza política como la Liga del Sur, y su posterior continuador, que era también un partido programático que aspiraba a representar tanto a la ciudadanía como a intereses sociales (corporativos) de ciertos sectores. Para la descripción del PS en clave local, ver Falcón (2005a: 166-175, 205-207).

${ }^{17}$ En ese sentido, una de las últimas líneas que tenemos de Ricardo Falcón son para afirmar la "consideración especial" que debía tener Rosario para un estudio de los orígenes del socialismo argentino, diferente tanto al escenario porteño como al de otras localidades del interior (Falcón, 2011: 45).
} 
obrera se agregan los chacareros y las clases medias urbanas), imaginando un bloque histórico inspirado por el socialismo, retomando una tesis de J. Aricó. ${ }^{18}$

Aquí, al adentrarse en lo que entendía por identidades, regresa también al problema de la formación de la clase obrera. Distinguía ahora, en primer lugar, un nivel estructural, que relaciona las modalidades de existencia del proletariado con el tipo de relación de producción imperante; en segundo lugar, un proceso interno, donde confrontan fuerzas centrípetas (de donde surge, por ejemplo, la solidaridad de clase), y centrífugas (donde aparecen otras divisorias de género, etnia, etc.); y finalmente, un proceso externo, que encarna las interacciones variadas con el Estado y la burguesía. De estos tres niveles surgía una identidad de clase, que sufría mutaciones a través del tiempo, pero se expresaba siempre en forma discursiva (Falcón, 2000a: 212-214). Ciertamente, el análisis en términos de "identidad" se oponía aquí a la visión marxista de la "consciencia de clase".

Entre los elementos que formaban parte de la identidad socialista en la clase obrera, es decir su discurso hacia ella, Falcón apuntaba primordialmente tres: el internacionalismo, que contrariamente al universalismo, no desconocía el elemento nacional; la acción política, que suponía interactuar con niveles estatales e incluso su inserción en algunas de sus instancias, como el parlamento; y la autonomía obrera en el plano sindical (Falcón, 2000a: 218).

No deja de ser significativo que a partir de ese momento Ricardo Falcón dedicara sus esfuerzos a escribir un libro sobre el socialismo argentino. Si se puede aseverar que el impulso que estaba recibiendo por entonces la investigación en torno al Partido socialista fue para él un aliciente en esta empresa, ella desnudaba a su vez las limitaciones de la que adolecía ahora su biblioteca, como se puede ver en el conjunto de referencias que pueblan sus dos últimos trabajos (Falcón, 2008 y 2011). Y aunque por lo esencial no era un trabajo de primera mano, ni siquiera con respecto a sus propias investigaciones precedentes, su erudición servía de marco para algunas ideas novedosas en torno al nuevo problema. Por lo pronto podía denunciar el "doble anacronismo" con que ciertos trabajos precedentes habían encarado el problema de la identidad socialista, ya sea porque se analizaba al socialismo en una óptica posterior a la Revolución de 1917 y con una óptica leninista sobre el partido, el Estado y la fase imperialista del capitalismo, o porque se lo abordaba tras la experiencia del peronismo en Argentina, y su posterior valoración como movimiento nacionalista revolucionario (Falcón, 2008: 3).

La identidad era luego abordada como "resultante de un conjunto de discursos sobre otros discursos o sobre hechos", que permitían constituir relatos. A su vez las identidades políticas eran forjadas tanto por la experiencia de un sujeto social como por la apropiación de una

\footnotetext{
${ }^{18}$ Queda pendiente una reconstrucción más cuidada del lazo de Falcón con otros autores -el citado Aricó ante todo, pero también Juan Carlos Portantiero y Waldo Ansaldi, o aún, en otro plano Oscar Terán o los ya recordados Gutiérrez y Romero-, de los que se apropia conceptos, al mismo tiempo que los reformula críticamente.
} 


\section{Carlos Herrera}

tradición heredada. La primera dimensión se expresaba en el programa mínimo, pero, ante la ausencia de analogías históricas, estas eran formuladas con respecto a experiencias europeas (Falcón, 2008: 3 y Falcón, 2011: 14) ${ }^{19}$. Pero era necesario armarse, además, de una "tradición legitimadora", al mismo tiempo nacional e internacional, que tomará tanto la forma de la herencia como de la adquisición (Falcón, 2011: 14).

Falcón reconstituía con fineza los principales momentos de esa operación ideológica compleja, que partía de la herencia de la Revolución francesa, para materializarse en la Generación del '37, donde pensadores como Pierre Leroux, pero incluso Giuseppe Mazzini terminaban convergiendo, en particular en Esteban Echeverría. Pero, una vez más, no se trataba de apropiarse sólo de ideas, sino también de experiencias contemporáneas en el viejo continente, como la Revolución de 1848 y la figura del derecho al trabajo.

La doble legitimidad que había distinguido lo hacía adentrarse en las lecturas de la tradición en Justo e Ingenieros. Pero Falcón proponía una mirada -arqueológica, en sus propios términosque fuera consciente de profundos cortes producidos en las distintas etapas de conformación del movimiento, que presentaba afluentes diversos en el país a partir de 1880 (Falcón, 2008: 16). Entre las principales figuras del incipiente movimiento, de Lallemant a Justo, pero también de Nocke a Mauli, pasando por Esteban Jiménez había profundas diferencias, como se expresaban en los primeros congresos (Falcón, 2008: 22-23).

El aporte historiográfico principal del trabajo residía sin duda en la idea de "analogías", como necesidad específica en la construcción de la experiencia socialista, y se justificaban en Justo por el acelerado proceso del desarrollo capitalista en Argentina. No se trataba de "copiar" sino de establecer comparaciones "para delimitar más precisamente un programa y un curso de acción propios en el ámbito nacional" (Falcón, 2008: 25) ${ }^{20}$. De hecho, se remontaban a la propia Generación del '37, y también a la presencia del fourierismo, pero se fueron precisando tras la constitución de la Internacional, en particular con el socialismo alemán, el laborismo inglés, y ya en el marco del proyecto de Justo con otras experiencias, como la belga. En ese marco reformista, Jaurès, como lo venían afirmando Aricó, y en menos medida Bernstein, formaban elementos de peso. Aunque, extrañamente, Falcón no abordaba aquí el caso Ferri (Herrera, 2015).

La identidad reformista que resultaba suponía alcanzar el objetivo de la colectivización de los medios de producción activando la palanca del poder político (Falcón, 2008: 29). A su vez, esta se podía declinar en varias características: considerarse un partido nacional e internacional, pero

\footnotetext{
${ }^{19}$ Comparar con Herrera (2017).

${ }^{20}$ En la misma dirección, se podrá anotar otro aporte metahistórico en la idea de "interferencias" en la evolución del movimiento de los trabajadores argentino en sus albores, provocadas por las periódicas micro-emigraciones europeas de carácter político a partir de 1852 (Falcón, 2011: 27). Por otro lado, Falcón se mostrará siempre atento a los trabajadores negros, así como a los trabajadores mestizos o indios, aunque no lograsen producir formas autónomas de organización (Falcón, 1999: 486-488).
} 
sobre todo un partido moderno, al ser orgánico en su organización, y programático, en el plano de las reivindicaciones. Esta dimensión era a su vez dual, como programa obrero, pero también republicano, es decir "democrático, popular, de reformas avanzadas". El PS era moderno también por su composición social, que atravesaba todas las capas más dinámicas de la sociedad de su tiempo, es decir "un partido de artesanos, obreros, empleados, en su mayoría extranjeros, con una activa minoría de profesiones liberales, entre los que se destacaban los médicos y los abogados", sin desmedro del peso, al menos en sus primeros años, de los "intelectualesobreros", que eran "generalmente artesanos con formación autodidacta" (Falcón, 2008: 30). Esta presencia alimentaba su fuerte tendencia a la pedagogía social, "un cierto iluminismo" que desembocaba en "un matiz tutelar sobre los trabajadores", la preocupación "de volver conscientes a los trabajadores, naturalmente inconscientes, a través de la propaganda, incluida la de los hechos", que, por cierto, no era propio únicamente de los socialistas (Falcón, 2011: 169). La complejidad de la identidad socialista aparecía como una evidencia -que fuera políticamente inestable era otro tema (Herrera, 2007)-. En síntesis, si la experiencia que representaba y legitimaba el programa socialista era nacional e internacional, sus intelectuales buscaban dotarlo de una tradición legitimadora, tanto como partido obrero que como fuerza republicana, nacional y democrática (Falcón, 2008: 30). De alguna manera, el concepto de identidad -he aquí el carácter de legado que tienen estas últimas investigaciones-, permitía a Falcón hacer una síntesis de sus antiguas posiciones, como la idea del programa "como expresión de los intereses materiales y morales del pueblo trabajador" (Falcón, 2008: 12).

En otro de los borradores de este proyecto inconcluso, Falcón avanzaba en la reconstrucción histórica del momento fundacional del PS, distinguiendo al menos dos fases en sus inicios, pero adentrándose únicamente en la que denomina "etapa del movimiento socialista", que iría de enero de 1882 y la fundación del club Vorwärts, a abril de 1894, con la creación del Partido Socialista Obrero Internacional (Falcón, 2011: 329). Esta etapa se caracteriza por "la confluencia de agrupamientos organizados sobre bases etno-lingüísticas, sindicales, mixtas o puramente políticas, con formas laxas de coordinación entre ellas y diversos grados de organicidad según los momentos", a lo que se agrega una permanente preocupación programática (Falcón, 2011: 33).

Al interior de esta etapa, Falcón distinguía diferentes períodos, cuyo número no se llega a estabilizar completamente en su manuscrito, pero que superan ese arco temporal de doce años, en la medida que abren la transición a nuevas mutaciones ${ }^{21}$. El primero de ellos iba de 1882 a 1887, y estaba dominado por la citada asociación de los socialistas alemanes, y está basado ante

\footnotetext{
${ }^{21}$ La cuestión de la identidad no aparece en primer plano, puesto que se trata de estudiar los "orígenes del movimiento socialista en Argentina; su transformación en partido; los momentos críticos de ese proceso; su inserción en el contexto más amplio del movimiento obrero y del conjunto de la vida política de la época y su consolidación, relativa, como estructura partidaria" (Falcón, 2011: 13).
} 


\section{Carlos Herrera}

todo en la propaganda (Falcón, 2011: 14, 32). El segundo momento corresponde a los años 1888-1890, y es donde se produce el encuentro entre movimiento obrero y socialismo, materializado por el acto del $1^{\circ}$ de mayo de 1890. Ya con el reflujo de las luchas obreras se inicia un tercer período, donde la construcción de un partido obrero se confunde con el movimiento sindical, y que se extendería hasta la creación de la Agrupación Socialista y la fundación de La Vanguardia. Surge luego el camino que lleva a una mayor centralización, que se expresa en 1894, cuando se consolida la primera organización, nacida de aquella Agrupación Socialista y su posterior convergencia con los grupos italianos y franceses. A partir de ese momento aparece un momento de transición que conduce a la era partidaria, que tiene un punto álgido en 1896 con el llamado "congreso constituyente", y que se consolida definitivamente hacia 1900, ya como un partido moderno.

Falcón recordaba que existía, además, una prehistoria del socialismo que se extendía de 1857 a 1881, dentro de la cual interactuaban el mutualismo, los periódicos social-republicanos, las primeras sociedades de resistencia o aun la presencia de la Asociación Internacional de Trabajadores en Argentina entre 1871 y 1874, en un mundo marcado por la inmigración europea (Falcón, 2011: 23-31), que retomaban la base empírica de sus mejores trabajos de los años 1980 y 1990, pero los orientaba ahora más directamente hacia el problema de la identidad de ese movimiento naciente.

La paradoja quiso que el momento de mayor atención al objeto socialista por parte de Ricardo Falcón, materializado por el recordado proyecto de escribir un libro exclusivamente dedicado al tema, coincidió con un desarrollo cada vez más agudo de la enfermedad social que lo aquejaba desde hacía tiempo, y que tornaba ya improbable su ambiciosa empresa. El riesgo de dejar ese conjunto de ideas e intuiciones en la ganga de sus circunstancias, que produjo errores, aproximaciones, blancos, debe ser, pues, conjugado.

Hay por lo pronto en este recorrido que había comenzado treinta años antes, y en que hemos reconocido al menos tres momentos, ciertas invariantes. La más importante de ellas es quizás la caracterización del PS a partir de su carácter programático. No era esa una muestra de originalidad, como sí lo era, en cambio, el carácter inestable de su proyecto que Falcón percibía en él, con sus dos componentes internos de integración, el corporativo y el político, que eran de naturaleza distinta. Ligada a esta primera observación importante, Falcón proponía una hipótesis sugerente para captar sus problemas estructurales, cuando afirmaba que "cada vez que lograban una cierta inserción en los medios obreros e intentaban combinarla con la acción política, se 
generaban fuertes tensiones, crisis e incluso escisiones", trayendo a colación "las luchas internas y rupturas de 1897 y 1898-1900; las de 1904-1906, las de 1918-1921 y aun las de fines de la década del treinta y del período preperonista" (Falcón, 1987: 218). En definitiva, el propio Partido Socialista - al menos en formación, interesa recalcarlo- se presentaba en su pluma como "un partido obrero y como un partido de izquierda, popular, de reformas democráticas avanzadas, susceptibles de interesar a las clases medias urbanas y rurales" (Falcón, 2008: 12). Independientemente de los aportes que Falcón hiciera en tiempos en que el Partido Socialista no era objeto de la historiografía académica, como conectar la historia del socialismo argentino con el movimiento internacional, podemos encontrar otros sugerentes planteos que se proyectan en el tiempo. Uno, particularmente importante, es llamar la atención sobre la reconstrucción del período de formación del socialismo argentino, en particular lo que llamó con agudeza el "movimiento socialista", es decir el debate y las organizaciones previas al Congreso de 1894. Conectados de algún modo con esta preocupación, sus últimos trabajos muestran, además, un interés prometedor por una reflexión en términos de "identidad", que adelantaba algunos ensayos que fueron publicados posteriormente.

En suma, y a riesgo de esquematizar, podemos situar los aportes de Falcón tanto en el ámbito metodológico (las conexiones que exige el tema, tanto entre historia social, historia de las ideas e historia política, como en las escalas), como en el plano historiográfico (con meta-conceptos como "analogía" o aun "interferencia"), sin olvidar, por supuesto, sus contribuciones históricas propiamente dichas (como sus periodizaciones de los inicios del socialismo argentino en el siglo XIX o aún su temprano estudio conectado y comparado de las diferentes expresiones de las izquierdas). Muchos de estos aspectos, que dejara inconclusos o en estado embrionario, ya han comenzado a ser retomados por las nuevas investigaciones en curso. Esta "actualidad" de la agenda falconiana sobre el socialismo argentino es quizás la mejor certeza que nos queda de la calidad de su labor como historiador.

\section{Textos de Falcón}

Falcón, R. (1979). "Lucha de tendencias en los primeros congresos del Partido Socialista Obrero Argentino - 1896-1900", Apuntes. Para la historia del movimiento obrero y antiimperialista latinoamericano, año $1, \mathrm{n}^{\circ} 1$, octubre-diciembre.

(1984). Los orígenes del movimiento obrero (1857-1899), Buenos Aires, CEAL.

(1985). "Los intelectuales y la política en la visión de José Ingenieros", ahora en Estudios sociales, $2011, \mathrm{n}^{\circ} 40$.

(1986). El mundo del trabajo urbano (1890-1914), Buenos Aires, CEAL. 


\section{Carlos Herrera}

(1987). "Izquierdas, régimen político, cuestión étnica y cuestión social en Argentina (1890-1912)", ahora en Estudios sociales, 2011, n 40.

(1988). "Aspectos del proceso de formación de la clase obrera en Argentina (18701914)", Revista de Historia, Centro de Investigaciones Históricas, Universidad de Costa Rica, $\mathrm{n}^{\mathrm{o}} 17$, enero-junio.

(1989). "Problemas teóricos y metodológicos en la historia del movimiento obrero en Argentina”, en Zubillaga, C. (ed.), Trabajadores y sindicatos en América Latina, Montevideo, Consejo Latinoamericano de Ciencias Sociales.

(1992). "Elites urbanas, rol del Estado y cuestión obrera (Rosario, 1900-1912)", Estudios sociales, $\mathrm{n}^{\circ} 3$.

(1999). “Los trabajadores y el mundo de trabajo", en M. Bonaudo (ed.), Nueva Historia Argentina, t. IV, Liberalismo, Estado y orden burgués (1852-1880), Buenos Aires, Sudamericana.

(2000a). “Militantes, intelectuales e ideas políticas”, en R. Falcón (ed.), Nueva Historia Argentina, t. VI, Democracia, conflicto social y renovación de ideas (1916-1930), Buenos Aires, Sudamericana.

(2000b). "Notas sobre la cuestión social en Argentina", Cuadernos del CIESAL, año 6, $n^{\circ} 6-7$.

(2005a). La Barcelona Argentina. Migrantes, obreros y militantes en Rosario. 18701912, Rosario, Laborde Editor.

(2005b). "El renacimiento socialista", La Capital, 30 de octubre de 2005.

(2008). Notas sobre la formación de la identidad socialista en Argentina, Rosario, Laborde Editor.

(2011). “Orígenes del movimiento socialista en Argentina. (Prólogo. Capítulo I y II)”, Cuadernos del Ciesal, año 8, $\mathrm{n}^{\circ} 10$, julio-diciembre.

Falcón, R y Montserrat, A. (2000). “Estado, empresas, trabajadores y sindicatos”, en R. Falcón (ed.), Nueva Historia Argentina, t. VI, Democracia, conflicto social y renovación de ideas (1916-1930), Buenos Aires, Sudamericana.

\section{Bibliografía}

Acha, O. (2008). La nueva generación intelectual. Incitaciones y ensayos, Buenos Aires, Herramienta.

Camarero, H. y Herrera, C. (2005). "El Partido Socialista en la Argentina: nudos históricos y perspectivas historiográficas", en H. Camarero, C. M. Herrera (eds.), El Partido Socialista en 
Argentina: sociedad, política e ideas a través de un siglo, Buenos Aires, Prometeo, 2005, p. 973.

Glück, M. (2011). “Un intelectual orgánico y la historia de las ideas”, Estudios sociales, n 40.

Gotta, C. y Múgica, M. L. (2008). “Entrevista a Ricardo Miguel Falcón”, Itinerarios, Año 2, nº 2.

Herrera, C. (2007). Las huellas del futuro. Breve historia del Partido Socialista en Argentina, Buenos Aires, La Vanguardia.

Herrera, C. (2015). "El Partido Socialista ante Enrico Ferri", Archivos de historia del movimiento obrero y la izquierda, ${ }^{\circ}$ 6, marzo, p. 73-93.

Herrera, C. (2018). "La construcción de un socialismo argentino en torno a Alfredo L. Palacios", Estudios sociales, vol. 55, n 2, 2018, p. 91-120.

Nieto, A. (2013). "Los usos de E. P. Thompson en la historiografia 'argentina': un itinerario posible", Rey Desnudo. Revista de libros, año 2, n 3.

Poy, L. (2013). "Ricardo Falcón (1945-2010). Alcances y límites de una propuesta para el estudio del mundo de los trabajadores en Argentina", Archivos de historia del movimiento obrero y las izquierdas, $\mathrm{n}^{\circ} 3$.

Romero, L.A.(1987). "Los sectores populares en las ciudades latinoamericanas del siglo XIX: la cuestión de la identidad”, Desarrollo económico, vol. 27, n 106, julio/septiembre.

Romero, L. A. (1995). "Introducción”, a L. H. Gutiérrez y L. A. Romero, Sectores populares, cultura y política. Buenos Aires en la entreguerra, Buenos Aires, Sudamericana.

Sábato, H. y Romero, L.A. (1992). Los trabajadores de Buenos Aires. La experiencia del mercado: 1850-1880, Buenos Aires, Sudamericana.

Recepción: 06/09/2021

Evaluado: 11/10/2021

Versión final: 15/11/2021 